\title{
FUNÇÃO SOCIAL DOS SERVIÇOS NOTARIAIS E DE REGISTRO SOB A PERSPECTIVA DA CONSTITUIÇÃO FEDERAL DE 1988
}

\section{Cintia Maria Scheid ${ }^{*}$}

\begin{abstract}
Resumo
O objetivo do trabalho é analisar a função social dos serviços notariais e registrais na perspectiva da $\mathrm{CF} / 88$. Com método dedutivo, pesquisa legislativa, bibliográfica e jurisprudencial, buscou-se verificar como a função social dessa atividade foi influenciada pela $\mathrm{CF} / 88$. Igualmente, foi analisado de que forma a sociedade é impactada pela prestação desses serviços, considerando que evoluem pari passu com as necessidades sociais e econômicas de onde estão inseridos. Conclui-se que são serviços acessíveis e idôneos, cujos efeitos, amparados pela segurança jurídica decorrente da sua fé pública, previnem demandas judiciais. São, efetivamente, importantes instrumentos ao exercício da cidadania e dos direitos fundamentais.

Palavras-chave: Serviços notariais e registrais. Função Social. Constituição Federal de 1988. Segurança jurídica. Extrajudicialização.

\section{THE SOCIAL ROLE OF NOTARY AND REGISTRY SERVICES FROM THE PERSPECTIVE OF FEDERAL CONSTITUTION OF 1988}

\begin{abstract}
This paper aims to analyze the social role of notary and registry services considering the $\mathrm{CF} / 88$. With a deductive method, and legislative, bibliographic and jurisprudential research, we verify how the $\mathrm{CF} / 88$ influenced the social role of this activity. Likewise, it was analyzed how society is impacted considering that they services evolve pari passu with the social and economic needs of which they are part. It is concluded that they are accessible and trustworthy services, whose effects, by the legal security from public faith, prevent judicial demands. They are, in fact, important instruments for the exercise of citizenship and fundamental rights.
\end{abstract}

Keywords: Notary and registry services. Social role. Federal Constitution of 1988. Legal security. Extrajudicialization.

\footnotetext{
* Pós-doutoranda em Direito Humanos - Universidad de Salamanca (USAL), Espanha. Doutora em Função Social do Direito/Constitucionalização dos Institutos de Direito Privado - Faculdade Autônoma de Direito de São Paulo (FADISP). Mestre em Direitos Sociais e Políticas Públicas/Políticas Públicas de Inclusão Social Universidade de Santa Cruz do Sul (UNISC). Especialista em: Direito do Estado - Universidade Federal do Rio Grande do Sul (UFRGS); Direito Notarial e Registral - Universidade do Sul de Santa Catarina (UNISUL); Direito Registral Imobiliário (UNIASSELVI). MBA - Escuela Superior de Administración y Dirección de Empresas (ESADE) Barcelona, Espanha. Bacharel em Direito pela Pontifícia Universidade Católica do Rio Grande do Sul/PUC-RS. Tabeliã concursada do $4^{\circ}$ Tabelionato de Protesto de Títulos e Documentos de Dívida de Curitiba, Paraná. Ex-titular concursada do $1^{\circ}$ Serviço de Registro Civil das Pessoas Naturais e $5^{\circ}$ Tabelionato de Notas de Maringá, Paraná (2009 a 2017), e do Serviço Notarial e Registral de Jaquirana, Comarca de Bom Jesus, Rio Grande do Sul (2007 a 2009). E-mail: titular@4protestocuritiba.com.br Endereço: Rua Visconde do Rio Branco, $n^{\circ}$ 1488, salas 506/511, Centro, CEP: 80.420-210 - Curitiba/PR.
} 


\section{INTRODUÇÃO}

Os serviços notariais e de registro, serventias extrajudiciais conhecidas como cartórios, são importantes instrumentos à disposição da população e do Poder Público para garantir a publicidade, autenticidade, segurança e eficácia de atos jurídicos do cotidiano de todos os cidadãos.

Esses serviços estão previstos na $\mathrm{CF} / 88$, em seu artigo 236 , e são de tamanha importância para a sociedade que a Constituição Federal determina, expressamente, que "o ingresso na atividade notarial e de registro depende de concurso público de provas e títulos". Mediante concurso público, portanto, os serviços notariais e de registro são delegados pelo Poder Público e exercidos em caráter privado, sob a fiscalização do Poder Judiciário.

A importância desses serviços para a sociedade vem, paulatinamente, sendo fortalecida com o reconhecimento de sua função social, notadamente com a extrajudicialização de alguns procedimentos, dando maior liberdade às partes para a escolha do meio mais adequado às suas demandas, de forma segura, além de proporcionar economia e celeridade, caracterizando-se, ainda, como importantes instrumentos para a realização de políticas públicas.

Nesse contexto, os serviços notariais e registrais são atores relevantes para a concretização dos direitos dos cidadãos, garantindo a cidadania e direitos fundamentais, e, por conseguinte, a dignidade da população, o que evidencia a sua função social, permitindo, inclusive, a ampliação da atuação desses serviços, conforme será demonstrado no presente trabalho.

Sob essa perspectiva, o presente trabalho abordará, num primeiro momento, resumidamente, a configuração dos serviços notariais e de registro no ordenamento jurídico brasileiro, notadamente a partir da Constituição Federal de 1988. Em seguida, serão tecidas considerações sobre a fé pública no âmbito dos serviços notariais e de registro, como um dos pilares fundamentais para a consecução da função social desses serviços, para, então, serem apresentados alguns aspectos relevantes sobre a função social e a atividade extrajudicial notarial e de registro. Por fim, será contextualizada, ainda que de forma sucinta, a função social dos serviços notariais e de registro na atualidade. Para tanto, foi utilizado método hipotético-dedutivo, e realizada pesquisa legislativa, bibliográfica e jurisprudencial, como também consulta a fontes estatísticas. 


\section{OS SERVIÇOS NOTARIAIS E DE REGISTRO NA CONSTITUIÇÃO FEDERAL DE 1988}

As atividades notariais e de registro acompanham a vida civil do ser humano desde o começo de sua organização em sociedade, evoluindo com as suas necessidades, assegurando direitos de forma a desempenhar papel fundamental na prevenção de litígios, configurando-se em importante instrumento de estabilização social.

Por certo, a razão ontológica dos serviços notariais e de registro é e sempre foi no sentido de garantir publicidade, autenticidade, segurança e eficácia dos atos jurídicos, o que evidencia a função social intrínseca à sua razão de ser.

Sem embargo, o tratamento legislativo a eles dispensado nem sempre compreendeu a amplitude e a importância de sua atuação, notadamente no Brasil, onde, inicialmente, a configuração desses serviços foi herdada de Portugal, sendo exercida por pessoas próximas ao Poder (FERREIRA, 2013, p. 409).

Antes da CF/88, o tabelião era vinculado ao Poder Judiciário como serventuário da justiça. A matéria relativa à atividade notarial e de registro era de competência estadual, regida pelas respectivas leis de organização judiciária (artigo 144, $\S 5^{\circ}$, da EC no 01/69, e artigo $6^{\circ}$, IV, da Lei $\mathrm{n}^{\mathrm{o}}$ 5.621/70). "Daí a afirmar-se que as qualidades e os defeitos do notariado brasileiro, até então, correspondiam ao resultado de maior ou menor eficiência do Poder Judiciário na administração dos funcionários” (FERREIRA, 2013, p. 409).

Assim, inexistia tratamento legislativo único para o serviço notarial e de registro, de maneira que cada unidade federativa regulamentava o seu funcionamento como melhor lhe aprouvesse. Essa discrepância certamente constituiu um entrave ao aperfeiçoamento da atividade em nível nacional, retardando o seu desenvolvimento para o melhor atendimento de sua função social.

A "oficialização" (estatização) geral da atividade notarial e de registro, oriunda da $E C n^{\circ} 07 / 77$, prevista no artigo 206, foi revogada com a promulgação da $E C n^{\circ} 22 / 1982$, que excluiu a previsão de oficialização das serventias extrajudiciais, mantendo somente a exigência para as judiciais. Houve, assim, a possibilidade de reprivatização da atividade notarial e de registro, de forma que as serventias extrajudiciais passaram a seguir o regime estabelecido pelos Estados, Distrito Federal ou Territórios, que poderia ser estatizado ou privado (ZOCKUN, 2018, p. 50). 
Essa situação mudou, substancialmente, com a $\mathrm{CF} / 88$, que incluiu as disposições relativas à atividade no Título IX - Das Disposições Gerais Constitucionais, e não mais dentre as normas concernentes à organização dos Poderes, passando a denominar a atividade de serviços notariais e de registro, que são aqueles "prestados pessoalmente por notários ou tabeliães, e registrador, ou oficial de registro, ou por seus prepostos, sob a responsabilidade daqueles, em serventias voltadas para o atendimento do povo em geral" (CENEVIVA, 2002, p. 22).

Nos termos do artigo 236 da CF/88, esses serviços são exercidos em caráter privado, por delegação do Poder Público, mediante aprovação em concurso público de provas e títulos.

Dessa dicção constitucional extrai-se o cerne da transformação da atividade notarial e de registro com o advento da $\mathrm{CF} / 88$, não mais atrelados às normas de organização dos poderes, constituindo-se em autêntica delegação pública de função pública desempenhada por particulares sob a forma privada.

O STF, na ADI 3.089-2/DF, posicionou-se no sentido de que essa delegação, a partir da CF/88, não é uma faculdade do Poder Público, tal como são a concessão e a permissão do artigo 175 da $\mathrm{CF} / 88$. As atividades notariais e de registro devem ser, obrigatoriamente, exercidas por particulares, pessoas físicas, mediante delegação após aprovação em concurso público, sendo fiscalizadas exclusivamente pelo Poder Judiciário.

Também consolidou o entendimento de que esses serviços têm natureza jurídica de atividades próprias do Poder Público (atividades de natureza pública), mas obrigatoriamente exercidas em caráter privado, em face do disposto no artigo $236 \mathrm{da} \mathrm{CF} / 88$.

O que se quer é que pessoas privadas e não entes públicos prestem essa particular espécie de função administrativa. O que se quer evitar não é a titularidade do Estado no exercício dessa função (pois quem não é titular de uma atividade não pode delegá-la), mas a sua execução, a sua prestação, por órgãos públicos. O que se quer garantir é que não seja estatizada a prestação desta atividade, ou seja, que apenas pessoas privadas possam, fazendo as vezes do estado, prestála. (FIGUEIREDO, 2010, p. 72)

De forma resumida, são típicas atividades estatais, mas não serviços públicos propriamente, categorizando-se como função pública, como são as "de legislação, justiça, diplomacia, defesa nacional, segurança pública, trânsito, controle externo e tantos outros cometimentos que, nem por serem de exclusivo senhorio estatal, passam a se confundir com 
serviço público". Assim, são "serviços notariais e de registro, simplesmente, e não qualquer outra atividade estatal", conforme entendimento do STF na mencionada ADI 3.089-2/DF.

Na classificação de Celso A. B. de Mello, os notários e registradores ajustam-se aos "particulares em colaboração com a Administração", espécie do gênero agentes públicos. Definem-se como sujeitos que, sem perderem sua qualidade de particulares, ou seja, de pessoas alheias à intimidade do aparelho estatal, exercem função pública, como agentes delegados (MELLO, 2005, p. 232).

A exigência de concurso público não tem o condão de caracterizar os tabeliães e registradores como servidores públicos, nem infirma a forma de prestação privada, mas tão somente permite "a escolha, com base em critérios isonômicos, da pessoa que maior capacitação demonstra para o exercício da função" (FIGUEIREDO, 2010, p. 77-78).

Tratando-se de atividade de natureza pública desempenhada de forma privada, é essencial que a seleção do agente delegado competente observe parâmetros de idoneidade e isonomia, cujo resultado deve apontar a pessoa mais capacitada para o exercício de função tão cara à estabilidade das relações sociais. Nesse cenário, o concurso público ainda é o meio adequado para alcançar tais fins e atender aos princípios da legalidade, impessoalidade, moralidade, publicidade e eficiência, corolários da administração pública de qualquer das esferas dos Poderes, consoante o artigo 37 da CF/88.

A fim de dar concretude a esse novo quadro desenhado pela $\mathrm{CF} / 88$, o $\S 1^{\circ}$, do artigo 236, atribuiu ao legislador ordinário a competência para editar normas de regulamentação da atividade, o que ocorreu com a publicação da Lei n ${ }^{\circ}$ 8.935, em 18 de novembro de 1994.

Essa lei trouxe ao ordenamento jurídico brasileiro, pela primeira vez, o estatuto que sistematizou os serviços notariais e de registro, delineando o âmbito dessas atividades mediante o estabelecimento das atribuições e competências de cada uma delas ${ }^{1}$, mas sob princípios e finalidades comuns a todas. Os serviços notariais e de registro passaram a contar, portanto, com regime jurídico próprio.

Nesse sentido, preconiza, no artigo $1^{\circ}$, que "serviços notariais e de registro são os de organização técnica e administrativa destinados a garantir a publicidade, autenticidade, segurança e eficácia dos atos jurídicos”, e complementa, no artigo $3^{\circ}$, o perfil da atividade ao

\footnotetext{
${ }^{1}$ Art. $5^{\circ}$ Os titulares de serviços notariais e de registro são os: I - tabeliães de notas; II - tabeliães e oficiais de registro de contratos marítimos; III - tabeliães de protesto de títulos; IV - oficiais de registro de imóveis; V oficiais de registro de títulos e documentos e civis das pessoas jurídicas; VI - oficiais de registro civis das pessoas naturais e de interdições e tutelas; VII - oficiais de registro de distribuição.
} 
prever que os tabeliães e registradores, são profissionais do direito, dotados de fé pública, a quem é delegado o exercício da atividade.

Essa nova configuração da atividade conduz a um regime jurídico e de atuação dos serviços notariais e de registro completamente renovado, imprimindo-lhe maior dinamismo, acompanhado de mais preparo técnico e responsabilidades dos profissionais do direito que recebem a delegação desses serviços por concurso público.

Walter Ceneviva afirma que o termo serviço posto pela lei expressa o trabalho técnico e especializado realizado pelos tabeliães e registradores, mediante delegação, e que se desenvolve de forma independente e sob a administração privada desses profissionais, embora sujeito à fiscalização do Poder Judiciário (CENEVIVA, 2002, p. 21).

O artigo 28, da Lei $n^{\circ} 8.935 / 94^{2}$, veicula, de forma expressa, a independência dos tabeliães e registradores no exercício de suas atribuições. Não se trata, portanto, “de um funcionário hierarquizado, submetido na sua actuação a ordens superiores, mas de um oficial independente que decide por si" (PEREIRA, 1994, p. 58), ainda que sujeito a eventual fiscalização a posteriori pelo Poder Judiciário. Dessa forma, o sistema notarial e registral brasileiro está conectado ao Poder Judiciário não como subordinado hierárquico, mas como um parceiro para a realização de direitos dos cidadãos.

Essa independência alcança não só o exercício das atribuições típicas dos tabeliães e registradores, mas também tudo aquilo que diga respeito à gestão dos serviços nos seus aspectos administrativo e financeiro, sempre com o intuito de obter a melhor qualidade na prestação dos serviços.

O serviço delegado não deixa de ser uma função pública de efeitos jurídicos; só que o modo da sua execução, com liberdade e organização e gestão administrativa, fica confiado à discricionariedade do delegatário. A fiscalização judiciária, técnica ou disciplinar, não envolve subordinação hierárquica, suscitando, ao revés, um certo regime especial de coordenação e colaboração. (CARMO, 2002, p. 30)

A delegação, conforme o artigo $3^{\circ}$ da lei, é realizada a um profissional do direito, ou seja, aquele cuja área principal de atividade envolve a aplicação da lei envolve atividade remunerada (CENEVIVA, 2002, p. 30).

\footnotetext{
${ }^{2}$ Art. 28. Os notários e oficiais de registro gozam de independência no exercício de suas atribuições, têm direito à percepção dos emolumentos integrais pelos atos praticados na serventia e só perderão a delegação nas hipóteses previstas em lei.
} 
$\mathrm{Na}$ condição de profissionais do direito, os tabeliães e registradores exercem sua atividade de forma independente. "Como jurista, e como qualquer jurista, o notário [e o registrador] enquanto técnico e operador do direito, intérprete da lei e meio da sua aplicação, só à lei deve obediência" (PEREIRA, 1994, p. 57). O agente delegado dos serviços notariais e de registro é, portanto, profissional do direito "com prerrogativas que o fazem participar da autoridade pública, donde a necessidade do controlo do exercício da sua actividade pelo Estado" (PEREIRA, 1994, p. 65).

Destarte, a instrumentalização da vontade das partes, o acolhimento ou rejeição de realização de determinado ato, a qualificação de títulos a registro ou para dar seguimento ao protesto, são desempenhados de forma independente, sem interferência direta do órgão fiscalizador na materialização desses atos.

Os serviços notariais e de registro destinam-se a garantir a publicidade, autenticidade, segurança e eficácia dos atos jurídicos, outorgando segurança aos usuários e à sociedade a respeito de tais atos, agindo os tabeliães e registradores como verdadeiros instrumentos de estabilização das relações sociais. Por essa razão, a Lei no 8.935/94 prevê que esses profissionais do direito são dotados de fé pública, atributo diretamente relacionado à função social que desempenham.

\section{FÉ PÚBLICA NO ÂMBITO DOS SERVIÇOS NOTARIAIS E DE REGISTRO}

A fé pública, no âmbito dos serviços notariais e de registro, caracteriza-se como um atributo da função exercida, que a lei chancela como garantia de segurança jurídica (CARMO, 2008, p. 76), pois é no exercício dessa atividade realizada por profissional do direito dotado de fé pública que se pretende declarar ou constituir direitos de forma pública, autêntica, segura e eficaz.

Nesse sentido, a fé pública que brinda os atos notariais e de registro, embora seja reforçada com os efeitos legais decorrentes desses atos (tais como prova plena ${ }^{3}$, presunção juris tantum de veracidade, efeitos substantivos, força executiva ${ }^{4}$ ), tem a sua fonte em sede

\footnotetext{
3 "Por plena prueba se entende aquella prueba que por sí sola basta para decidir. Es la medida de eficacia probatoria que tiene un instrumento, cuando por sí solo acredita el hecho controvertido. El documento que hace pela prueba, o plena fe, no requiere complemento alguno. El hecho que se halla representado en él, se tiene por verdade dentro del sistema de las pruebas. La plena prueba es el $100 \%$ de la eficacia probatoria". (COUTURE, 1954, p. 66).

4 Art. 215 Código Civil. A escritura pública, lavrada em notas de tabelião, é documento dotado de fé pública, fazendo prova plena. Art. 405 Código de Processo Civil. O documento público faz prova não só da sua formação, mas também dos fatos que o escrivão, o chefe de secretaria, o tabelião ou o servidor declarar que
} 
constitucional. Dito de outra forma, os alicerces normativos da atividade notarial e de registro estão fundamentados na Constituição Federal, é nela que se encontra a espinha dorsal da atividade, sendo os efeitos legais atribuídos à fé-pública que envolve esses atos decorrência natural dos ditames constitucionais. ${ }^{5}$ Dessa feita, "é a lei que se molda e se curva aos ditames magnos, que lhe servem de norte e baliza, e não o reverso, obviamente" (ZOCKUN, 2018, p. $85)$.

A fé-pública que exsurge da atividade notarial e de registro vem conformada com a presunção de validade que "provém do impessoal procedimento adotado na elaboração dos atos jurídicos pelo Estado ou por quem lhe faça as vezes, o que não se verifica na produção dos atos privados" (ZOCKUN, 2018, p. 94). Esse procedimento, realizado de forma impessoal $^{6}$ e imune aos interesses particulares, tipicamente parciais ${ }^{7}$, configura-se "em corolário da supremacia do interesse público e da indisponibilidade, pelo Poder Público, do interesse público" (ZOCKUN, 2018, p. 94). Daí que o valor probante do ato revestido de fé pública é de caráter legal, pois é o legislador, e não o juiz, quem define a sua eficácia (ZINNY, 2018, p. 68).

Nesse contexto, a higidez da fé pública nos atos realizados pelos notários e registradores reside na premissa de que "não é ato qualquer emanado de Notário ou oficial Registrador que faz fé pública, mas sim aqueles resultantes do regular exercício de suas

ocorreram em sua presença. Art. 427 Código de Processo Civil. Cessa a fé do documento público ou particular sendo-lhe declarada judicialmente a falsidade. Parágrafo único. A falsidade consiste em: I - formar documento não verdadeiro; II - alterar documento verdadeiro. Art. 406 Código de Processo Civil. Quando a lei exigir instrumento público como da substância do ato, nenhuma outra prova, por mais especial que seja, pode suprir-lhe a falta. Art. 784 Código de Processo Civil. São títulos executivos extrajudiciais: II - a escritura pública ou outro documento público assinado pelo devedor; XI - a certidão expedida por serventia notarial ou de registro relativa a valores de emolumentos e demais despesas devidas pelos atos por ela praticados, fixados nas tabelas estabelecidas em lei.

${ }^{5}$ Não fosse assim, "bastaría que un día cualquiera una ley estableciera que los documentos públicos, para hacer fe, deberían ser reconocidos judicialmente por los funcionarios otorgantes, o que las escrituras autorizadas por los escribanos deberían ser sometidas a análogo tratamiento, para que la fe pública como institución desapareciera". (COUTURE, 1954, p. 52).

${ }^{6}$ Interessante referir as vedações legais acerca do desempenho simultâneo de determinadas atividades pelos notários e registradores. Dispõe o artigo 25 da Lei 8.935/94 que o exercício da atividade notarial e de registro é incompatível com o da advocacia, o da intermediação de seus serviços ou o de qualquer cargo, emprego ou função públicos, ainda que em comissão. Visa, com isso, evitar que o procedimento seja eventualmente contaminado por interesses estranhos ao serviço.

7 "O sujeito do direito subjetivo, ao exercê-lo, terá um fim em mira; mas o fim influirá sôbre o bem ou fato; objeto do direito, mediatamente, através do sujeito. Diversamente, a atividade administrativa obedece a um fim, a que o agente é obrigado a adscrever-se, quaisquer que sejam as suas inclinações pessoais; e êsse fim domina e governa a atividade administrativa, a ponto de caracterizar-se, em vulgar, a boa administração pela impessoalidade". "A impessoalidade na determinação da vontade purifica o ato administrativo; fá-lo presumir isento de defeitos que o caráter pessoal lhe poderia imprimir, oriundo da variabilidade dos interêsses, de que a pessoa é suscetível”. (LIMA, 1951, p. 24-25). 
funções, segundo suas atribuições legais e com emprego da forma jurídica adequada" (AMADEI, 2014, p. 45).

Logo, o procedimento impessoal necessário para a configuração da fé pública exige que os notários e registradores observem, peremptoriamente, determinados requisitos (positivos e negativos): investidura para a realização daquele determinado ato; competência em razão do território para o qual receberam a delegação e onde deve ser realizado o ato; rogação para atuar, como regra geral; ausência de interesse pessoal no objeto do ato em questão, ou que este seja de interesse de seu cônjuge ou de parentes, na linha reta, ou na colateral, consanguíneos ou afins, até o terceiro grau (artigo 27 da Lei $n^{\circ}$ 8.935/94) ${ }^{8}$; inexistência de notificação realizada acerca de eventual suspensão, afastamento ou perda da atividade para a qual receberam a delegação. "Em todos esses casos a dação de fé é nula". (ZINNY, 2018, p. 156)

Uma vez atendidas essas condições, o direito confere à fé pública a função de dotar de certeza o ato que ela tenha por objeto, eliminando a incerteza "antes do processo e independentemente que esse surja" (ZINNY, 2018, p. 156).

[...] la eficacia sustancial de la fe pública es, en último término, consolidar el derecho poniéndole fuera de la incertitumbre. Es una forma de la llamada "realización espontánea del derecho". [...] Sustancia y forma aparecen em este fenómeno ligadas en un propósito de estabilidad y firmeza. [...] El derecho se realiza espontaneamente en la paz. ( COUTURE, 1954, p. 85)

É, portanto, da sua razão de ser atribuir “certeza fora do processo, seja para reduzir as suas probabilidades, seja para eliminar a fase de cognição (ZINNY, 2018, p. 96) ${ }^{9}$, ou sobretudo, para garantir à ordem jurídica uma base extraprocessual de estabilidade e

\footnotetext{
${ }^{8} \mathrm{O}$ artigo 27 da Lei $\mathrm{n}^{\circ}$ 8.935/94 prevê hipóteses de impedimento do exercício da atividade pelos notários e registradores.

${ }^{9}$ Quando o ato objeto da fé pública constitui-se em negócio do qual resulta crédito a que corresponda obrigação certa, líquida e exigível, "a dação de fé produz executividade, quer dizer, produz o efeito de permitir ao credor prescindir do processo de cognição para demandar a execução forçada". "Portanto a fé pública vem a substituir a coisa julgada, o que não tem nada de estranho, posto que ambas estão a serviço da segurança (que em um caso o direito consegue presumindo que o juiz não se equivoca; no outro, que o notário não mente)". (ZINNY, 2018, p. 100).

Art. 783 Código de Processo Civil. A execução para cobrança de crédito fundar-se-á sempre em título de obrigação certa, líquida e exigível. Art. 784. São títulos executivos extrajudiciais: [...] II - a escritura pública ou outro documento público assinado pelo devedor; [...] XI - a certidão expedida por serventia notarial ou de registro relativa a valores de emolumentos e demais despesas devidas pelos atos por ela praticados, fixados nas tabelas estabelecidas em lei.
} 
equilíbrio" (ZINNY, 2018, p. 68), pois os atos notariais e de registro, ao revestirem-se de fé pública, obstam que a coletividade oponha-se aos efeitos deles decorrentes, que somente poderão ser desconstituídos judicialmente ${ }^{10}$.

"La fe pública es, en resumen, uno de los más preciosos instrumentos de la convivencia humana en el orden pacífico" (COUTURE, 1954, p. 84). Portanto, a partir do atributo da fé pública os serviços notariais e de registro estão aptos a cumprir o seu fim de evitar a litigiosidade, ao assegurar juridicamente os atos por eles produzidos, garantindo a publicidade, autenticidade, segurança e eficácia que deles decorrem, e, assim, cumprir a função social que lhe é inata.

\section{FUNÇÃO SOCIAL E OS SERVIÇOS NOTARIAIS E DE REGISTRO: ALGUMAS CONSIDERAÇÕES}

A atividade notarial e de registro é reflexo da realidade na qual está inserida, sofrendo os impulsos políticos, econômicos, sociais e jurídicos característicos de cada época. A sua evolução, portanto, é o espelho de um conjunto de fatores ocorridos através do tempo, sempre ao lado da sociedade, o que é possível verificar com a sua atual formatação no cenário brasileiro.

Com efeito, o constitucionalismo contemporâneo brasileiro, sob o ângulo da função social do direito, ofereceu as condições ideais para que esses serviços possam, finalmente, demonstrar a sua capacidade de atuar de forma diferenciada perante a sociedade, sem a pecha de serviço burocrático e desnecessário que sempre lhe foi (e ainda é) impingida.

A partir dessa premissa, é que ocorre a ampliação do seu campo de atuação, desafogando o Poder Judiciário, tornando o Poder Executivo mais eficaz e, principalmente, empoderando a sociedade, que tem nesses serviços um meio ágil, seguro e eficiente de atendimento a várias de suas demandas sem a necessidade de intervenção do Estado, em homenagem à autonomia da vontade do cidadão. De fato, os serviços notariais e de registro passaram a ser, talvez, a

mais moderna instituição, voltada tipicamente para a comunidade, daí porque afastada a sua sujeição a qualquer tipo de órgão vinculado ao

\footnotetext{
10 "El instrumento público hace plena fe, aun frente a los terceros, en cuanto al hecho de haberse outorgado en su fecha. Nadie, ni las partes, ni los sucesores, ni los terceros, pueden desconocer la realidad del otorgamiento y la fecha del instrumento público, salvo prueba de falsedad. En el instrumento privado, en cambio, el hecho de haberse otorgado y su fecha, lo mismo que la representación de las obligaciones y sus descargos, sólo afectan a las partes y sus sucessores; no alcanzan, en cambio, a los terceiros". (COUTURE, 1954, p. 70).
} 
governo. Instituição, como se viu, porque verdadeiro corpo social, não efêmero, exigido e mantido como fenômeno social, para segurança da sociedade. (ERPEN, 1995. p. 272)

As serventias extrajudiciais, no desempenho das atividades notariais e de registro, demonstram aspectos relevantes de sua função social, sem qualquer ônus ao Estado. Dentre eles, é possível citar a democratização do acesso à orientação jurídica, diante de sua capilaridade no país; serem meios idôneos de prevenção e solução de conflitos, e também para a extrajudicialização de procedimentos; apresentarem-se como agentes de fiscalização tributária e de combate à lavagem de dinheiro e do financiamento ao terrorismo; auxiliarem políticas públicas; permitirem o acesso à cidadania; disponibilizarem melhoria contínua da tecnologia para ampliar o acesso ao serviço que prestam; e, atualmente, em face da pandemia da Covid-19, atuarem, especificamente, para a proteção patrimonial dos idosos, nos termos da Recomendação no 46, do CNJ, expedida em 22 de junho de 2020.

A importância da função social dessa atividade para a realização de diversos direitos do cidadão foi expressamente reconhecida com a edição do Provimento $\mathrm{n}^{\circ} 85$ do $\mathrm{CNJ}$, em 2019, ao dispor sobre o cumprimento da Agenda 2030 da Organização das Nações Unidas ONU, mediante a adoção dos seus Objetivos de Desenvolvimento Sustentável - ODS, pelas Corregedorias do Poder Judiciário e serventias extrajudiciais.

A Agenda possui 17 Objetivos de Desenvolvimento Sustentável e 169 metas, que buscam concretizar os direitos humanos, integrados e indivisíveis, a partir das três dimensões do desenvolvimento sustentável: a econômica, a social e a ambiental. O intuito é "mobilizar os meios necessários para implementar esta Agenda por meio de uma Parceria Global para o Desenvolvimento Sustentável revitalizada, com base num espírito de solidariedade global reforçada, concentrada em especial nas necessidades dos mais pobres e mais vulneráveis e com a participação de todos os países, todas as partes interessadas e todas as pessoas" (ONU, 2015, on-line).

A inclusão das serventias extrajudiciais para esse fim demonstra a sua relevância para a consecução dos objetivos fundamentais da República Federativa do Brasil, na construção de uma sociedade mais livre, justa e solidária, contribuindo para a garantia do desenvolvimento nacional, com a erradicação da pobreza e da marginalização, e, assim, com a redução das desigualdades sociais e regionais, promovendo o bem de todos, sem quaisquer formas de discriminação. Contribuem, inequivocamente, para o ODS 16, que visa "promover 
sociedades pacíficas e inclusivas para o desenvolvimento sustentável, proporcionar o acesso à justiça para todos e construir instituições eficazes, responsáveis e inclusivas em todos os níveis" (ONU, 2015, on-line), em um efetivo Estado de Direito e boa governança em todos os níveis e em instituições.

Para tanto, o Provimento $\mathrm{n}^{\mathrm{o}} 85$ prevê que compete às Corregedorias e às serventias extrajudiciais integrarem seus atos normativos aos ODS da Agenda 2030, demonstrando ao público a integração da atividade registral e notarial ao propósito de se alcançar a paz, a justiça e eficiência institucional.

Verifica-se, com esse breve relato, que a função social é característica indissociável dos serviços notariais e de registro, notadamente na atualidade sob o manto da CF/88.

\section{A FUNÇÃO SOCIAL DOS SERVIÇOS NOTARIAIS E DE REGISTRO NA ATUALIDADE}

Em face dos conhecimentos que lhe são requeridos para o desenvolvimento da atividade e da fé pública atribuída aos atos que realizam, os tabeliães e registradores possuem os requisitos necessários para a ampliação da função social que desempenham, pois é da natureza da atividade observar os interesses das partes, de forma imparcial, para garantir direitos com segurança jurídica, prevenindo litígios.

Nesse aspecto, a escolha feita pelo legislador constituinte quanto à atividade notarial e de registro constituir-se como função pública, de natureza administrativa, revela a importância atribuída à prática dos atos notariais e de registro.

Fossem estes atos meras declarações jurídicas que não guardam pertinência com a vida econômica e jurídica da nossa sociedade não haveria razão para que fosse atribuída a sua titularidade ao Estado e o seu exercício a agentes públicos que atuam em colaboração com a Administração. (FIGUEIREDO, 2010, p. 104)

De fato, esses serviços contribuem para evitar a insegurança e a imprevisibilidade jurídica, afastando potenciais prejuízos às relações sociais e econômicas que poderiam advir de situações jurídicas realizadas sem o devido preparo e cautela. Reduzem, assim, a probabilidade de demandas judiciais, auxiliando o erário ao impedir a sobrecarga do aparato judicial com os custos que o alto nível de judicialização requer.

É da natureza da atividade dos tabeliães e registradores essa atuação anterior à judicial, e para isso interpretam, integram e aplicam a lei, cumprindo "a tarefa de contribuir 
com a construção da ordem jurídica do futuro", pois, no seu mister, devem projetar as consequências dos atos que realizam (FISCHER; ROSA, 2013, p. 543). Nesse contexto, são curadores "da liberdade jurídica dos particulares, cuja autonomia se incumbe de orientar à justiça e à segurança" (FIGUEIREDO, 2010, p. 104).

Essa função é desenvolvida de forma espontânea e constante. Em virtude do contato intenso com as necessidades reais da sociedade, no desempenho diário das atividades, esse profissional do direito orienta diretamente os cidadãos acerca de seus direitos, de forma imparcial, e com fé pública. Dessa forma, a função desempenhada pelos tabeliães e registradores demanda, imprescindivelmente, "um conhecimento científico e uma especialização técnica cada vez mais complexos, face ao dinamismo próprio das relações negociais dos tempos que correm, obrigando-o, não raro, a ser o primeiro aplicador do Direito Novo, antes do juiz”. (FORMICOLA, 2013, p. 1268)

Outrossim, as serventias notariais e de registro proporcionam a democratização do acesso a um serviço jurídico de natureza pública qualificado, a custo baixo ou até mesmo sem ônus, franqueando às camadas mais necessitadas da população a possibilidade de serem orientadas por profissional de direito capacitado, dotado de fé pública, cuja prestação do serviço é feita sob sua exclusiva responsabilidade.

Ademais, o acesso ao serviço notarial e de registro é democratizado em face de sua imensa capilaridade, tendo em vista que são 13.440 serventias notariais e de registro no país, distribuídas entre os 5.570 municípios brasileiros (ANOREG/BR, 2020, p.6), alçando a atividade como importante instrumento de garantia da cidadania, especialmente aos menos favorecidos.

Por isso, a submissão da atividade notarial e de registro ao regime próprio do direito público fundamenta-se na sua importância no âmbito das relações privadas com importantes efeitos na estabilidade das relações sociais. "A sua relevância é tão grande para a ordem jurídica e econômica da nossa sociedade que não se entendeu como recomendável a sua atribuição à titularidade privada" (FIGUEIREDO, 2010, p. 105), mas somente a sua execução.

Diante da característica da atividade notarial e de registro para colaborar com a redução de litígios, a Lei $n^{\circ} 13.140 / 2015$, que dispõe sobre a mediação, abriu a possibilidade da sua realização pelos notários e registradores, no âmbito de suas respectivas competências.

Com a publicação dessa lei, das disposições do CPC de 2015 de que o Estado deve promover, sempre que possível, a solução consensual dos conflitos, e da incumbência do CNJ 
de consolidar uma política pública permanente de mecanismos consensuais de solução de litígios (Resolução no 125/2010, do CNJ), foi publicado o Provimento no 67, do CNJ, em 2018, regulamentando os procedimentos de conciliação e de mediação nos serviços notariais e de registro. Esse Provimento faculta aos tabeliães e registradores a realização dos procedimentos de mediação e conciliação, quando os direitos forem disponíveis ou, se indisponíveis, que admitam transação.

Ficou estabelecido, ainda, que serão realizadas sessões não remuneradas de conciliação e de mediação para atender demandas de gratuidade, como contrapartida da autorização para prestar o serviço, proporcionando à população carente um serviço de qualidade para a realização de seus direitos.

Importante referir que, especificamente em relação ao Protesto de Títulos e Documentos de Dívida, foi publicado pelo CNJ, também em 2018, o Provimento $\mathrm{n}^{\mathrm{o}} 72$, acrescentando a possibilidade de adoção de medidas de incentivo à quitação ou à renegociação de dívidas protestadas. Essa previsão permite a negociação entre as partes por meio da atuação do tabelião de protesto, evitando a propositura de ações judiciais ao incentivar a facilidade dos meios para o cumprimento das obrigações.

Ainda, importante ressaltar a possibilidade do protesto de decisões judiciais, que atribui ao Protesto de Títulos e Outros Documentos de Dívida importante papel no acesso à justiça, pois, além dos efeitos de recuperação do crédito, de fortalecimento do direito pelo caráter educativo e profilático do protesto perante a sociedade, também contribui ao respeito à autoridade da decisão judicial e ao descongestionamento do Poder Judiciário. De fato, “a necessidade de respeito às instituições - e a decisão judicial se insere nesse contexto - é um dos fundamentos do Estado de Direito" (WAMBIER, 2015, p. 264).

Conforme levantamento realizado pelo relatório Justiça em Números 2020: ano-base 2019, do Conselho Nacional de Justiça, a Execução Fiscal e a Execução Extrajudicial (não fiscal) correspondem aos segundo e terceiro lugares na escala da taxa de congestionamento ${ }^{11}$

11 Conforme o relatório "Justiça em Números 2020", taxa de congestionamento é o "indicador que mede o percentual de casos que permaneceram pendentes de solução ao final do ano-base, em relação ao que tramitou (soma dos pendentes e dos baixados). Cumpre informar que, de todo o acervo, nem todos os processos podem ser baixados no mesmo ano, devido à existência de prazos legais a serem cumpridos, especialmente nos casos em que o processo ingressou no final do ano-base.”. (CNJ, 2020, p.92). 
do Poder Judiciário em relação às execuções, representando, respectivamente, 86,9\% e 82,4\%, no primeiro grau de jurisdição (CONSELHO NACIONAL DE JUSTIÇA, 2020, p.155) ${ }^{12}$.

Nesse sentido, a previsão do artigo 517 do Código de Processo Civil de que a decisão judicial transitada em julgado poderá ser levada a protesto depois de transcorrido o prazo para pagamento voluntário previsto no artigo 523, é instrumento de extrema importância na atual conjuntura judicial.

De fato, a salutar atuação preventiva dos tabeliães e registradores é fundamental para a melhoria da prestação jurisdicional, atualmente sobrecarregada com questões que podem tranquilamente ser atribuídas aos serviços notariais e de registro. Carnelutti, em conferência sobre a figura jurídica do notário, realizada na cidade de Madri, em 1950, afirmou que quanto mais notário, menos juiz, pois quanto mais conselho do notário, quanto mais consciência do notário, quanto mais cultura do notário, menor é a possibilidade de lide, e, assim, muito menor é a necessidade do juiz (CARNELUTTI, 1951, p.11).

Essa célebre frase é muito atual, pois, após setenta anos, é possível atestar a sua propriedade com a extrajudicialização de alguns atos e procedimentos que passaram, neste século, a ser atribuição dos tabeliães e registradores, sob o manto da celeridade, economia e segurança jurídica. É o caso, por exemplo, da lavratura de inventário, partilha, divórcio, separação e restabelecimento extrajudiciais da sociedade conjugal, autorizada pela Lei $\mathrm{n}^{\circ}$ 11.441/2007, e regulamentada pela Resolução no 35/2007, do CNJ. Essa lei foi publicada em atenção ao "Pacto de Estado em favor de um Judiciário mais Rápido e Republicano", firmado pelos representantes dos Poderes Executivo, Legislativo e Judiciário, no ano de 2004 (BORTZ, 2009, p. 103). O primeiro ponto deste Pacto refere a necessidade de aprovação de medidas legislativas que tornem mais amplo o acesso à Justiça e mais célere a prestação jurisdicional (STF, 2004, on-line).

\footnotetext{
${ }^{12}$ De acordo com o relatório "Justiça em Números 2020", a maior taxa de congestionamento no primeiro grau de jurisdição, em 2019, foi da Execução Penal Privativa de Liberdade, com 87,4\%. Todavia, o próprio relatório faz a seguinte advertência: "É importante esclarecer que a taxa de congestionamento na execução penal deve ser lida com cautela, pois os altos valores alcançados não caracterizam baixa eficiência do Poder Judiciário; significam tão somente que as execuções estão sendo cumpridas, uma vez que, enquanto a pena do condenado estiver em execução, o processo deve permanecer no acervo. Dessa forma, a taxa de congestionamento dessa fase não pode ser avaliada como um indicador de desempenho. Cumpre informar, ainda, que o número de processos em execução penal difere do total de presos, já que um mesmo indivíduo pode ser réu em mais de um processo, assim como um mesmo processo pode ter mais de um réu preso". (CNJ, 2020, p.155).
} 
A medida foi acertada, pois, desde a edição da referida lei, em 2007, foram realizados milhões de atos dessa natureza, gerando economia de mais de 6,3 bilhões de reais, além de impactar positivamente o prazo de duração, que teve uma redução de praticamente 10 anos (ANOREG/BR, 2020, p. 44).

Outros exemplos de extrajudicialização e que repercutiram positivamente para o cidadão e para o Poder Judiciário, são a possibilidade de se fazer, diretamente no Registro Civil de Pessoas Naturais, procedimentos de reconhecimento de paternidade e maternidade biológica (Provimento $n^{\circ}$ 16/2012, do CNJ) e socioafetiva (Provimento ${ }^{\circ}$ 63/2017, do CNJ), e de averbação da alteração do prenome e do gênero nos assentos de nascimento e casamento de pessoa transgênero (Provimento $\mathrm{n}^{\mathrm{o}} 73 / 2018$ do $\mathrm{CNJ}^{13}$ ). ${ }^{14}$

Igualmente, é possível citar também a possibilidade da usucapião extrajudicial, prevista no artigo 216-A da Lei 6015/73, a partir da vigência do CPC de 2015, que pode ser realizada no âmbito dos serviços de notas e de registro de imóveis.

Na esfera da recuperação de dívidas públicas, despontam os Tabelionatos de Protesto como opção de baixo custo e alta eficiência na cobrança do crédito tributário com a utilização do protesto para recuperar os valores pendentes em dívida ativa. Essa medida extremamente exitosa, sem qualquer custo ao Poder Público, auxilia para aliviar a sobrecarga do Judiciário e para o incremento dos recursos públicos necessários à realização de diversas políticas públicas decorrentes da $\mathrm{CF} / 88$.

Ademais, desde o Provimento $\mathrm{n}^{\circ} 86 / 2019$, do CNJ, foi prestigiada a acessibilidade isonômica aos usuários desse serviço, diante da possibilidade de encaminhamento de dívidas a

${ }^{13}$ Art. $4^{\circ} \mathrm{O}$ procedimento será realizado com base na autonomia da pessoa requerente, que deverá declarar, perante o registrador do RCPN, a vontade de proceder à adequação da identidade mediante a averbação do prenome, do gênero ou de ambos. $\S 1^{\circ} \mathrm{O}$ atendimento do pedido apresentado ao registrador independe de prévia autorização judicial ou da comprovação de realização de cirurgia de redesignação sexual e/ou de tratamento hormonal ou patologizante, assim como de apresentação de laudo médico ou psicológico.

${ }^{14}$ Ainda no âmbito do Registro Civil das Pessoas Naturais, é importante mencionar que, em razão da pandemia da Covid-19, em 2020, a Associação Nacional dos Registradores de Pessoas Naturais (Arpen-Brasil) "criou uma área especial no Portal da Transparência com as informações disponibilizadas pelos Cartórios de Registro Civil do Brasil sobre as causas de mortes constantes nos registros de óbitos lavrados pelos Cartórios de todo o País [...]“A atualização permanente do número de registros de óbitos em meio à pandemia de Covid-19 é uma iniciativa dos Cartórios de Registro Civil do Brasil, que desta forma reforçam seu compromisso de transparência com a sociedade, em cumprimento à Portaria $n^{\circ}$ 57/2020, do Conselho Nacional de Justiça (CNJ), que também incluiu a pandemia pelo novo coronavírus no Observatório Nacional de Questões Ambientais, Econômicas e Sociais de Alta Complexidade, de Grande Impacto e Repercussão, formado conjuntamente pelo CNJ e pelo Conselho Nacional do Ministério Público (CNMP)". (ANOREG/BR, 2020, p. 36). 
protesto sem a necessidade de pagamento prévio dos emolumentos, demais acréscimos legais e despesas, apresentando-se como ótima alternativa à judicialização.

Ainda, no exercício de sua função pública, os agentes delegados desempenham importante papel na fiscalização e arrecadação de toda espécie de tributos, além de taxas estaduais destinadas aos Tribunais de Justiça, à Defensoria Pública, ao Ministério Público, dentre outros repasses. Do ano de 2010 até 30 de setembro de 2020, foram arrecadados pelas serventias extrajudiciais, sem qualquer ônus ou encargo ao Poder Público, aproximadamente 542 bilhões de reais (ANOREG/BR, 2020, p.10).

É dever legal do notário e do registrador fiscalizar o recolhimento dos impostos incidentes sobre os atos que praticam no exercício da função. O CTN prevê, no artigo 134, VI, a responsabilidade solidária dos tabeliães e registradores pelos tributos devidos sobre os atos praticados por eles, ou perante eles, em razão do seu ofício. A ausência ou falha dessa fiscalização enseja penalidades administrativas, além do pagamento do tributo devido.

Também na seara de atribuição de fiscalização como responsabilidade dos agentes delegados, destaca-se o papel desempenhado no combate à lavagem de dinheiro e ao financiamento do terrorismo. Ciente da importante função social desempenhada pelas serventias extrajudiciais, o CNJ publicou o Provimento $n^{\circ} 88 / 2019$, que dispõe sobre os procedimentos a serem adotados pelos tabeliães e registradores visando à prevenção dos crimes de lavagem de dinheiro e do financiamento do terrorismo, com a devida comunicação dos atos suspeitos à Unidade de Inteligência Financeira - UIF, do Banco Central, a partir de 2020.

As serventias extrajudiciais também se destacam por fornecerem importantes informações estatísticas, quantitativas e qualitativas para os órgãos de controle e planejamento de políticas públicas. Os serviços de Registro Civil de Pessoas Naturais informam às entidades oficiais de previdência e assistência os óbitos registrados, contribuindo com o controle de fraudes nos proventos de aposentadoria. Também repassam informações sobre casamentos, nascimentos e óbitos à Polícia Federal, Polícia Civil, consulados, secretarias de saúde, institutos de identificação, dentre outros órgãos, mantendo seus cadastros atualizados. A presença das serventias extrajudiciais nos rincões mais afastados dos grandes centros permite um mapeamento detalhado das taxas populacionais.

Outro caso de sucesso de desburocratização e facilitação do acesso do cidadão ao serviço público foi o apostilamento de Haia de documentos nacionais pelas serventias 
extrajudiciais, que permitiu ao cidadão brasileiro dar autenticidade aos documentos nacionais no exterior (países signatários) sem ter que percorrer consulados ou o Itamaraty, ao custo de uma fração do sistema anterior. De 2017 a setembro de 2020, 5,6 milhões de documentos foram apostilados nas serventias extrajudiciais (ANOREG, 2020, p. 58).

Tamanha importância e eficiência dos serviços notariais e de registro, especialmente após o modelo estabelecido pela $\mathrm{CF} / 88$, fez com que, além da extrajudicialização de procedimentos, houvesse a atribuição de outras competências. Nesse sentido, a Lei $n^{\circ}$ 13.484/2017, tornou os Ofícios de Registro Civil de Pessoas Naturais em "Ofícios da Cidadania", possibilitando a oferta da emissão de documentos como o registro geral de identidade e cadastro de pessoa física. Beneficiam-se a população residente em locais distantes e de difícil acesso às médias e grandes cidades que detêm esses serviços, e também a população destes centros urbanos, já que haverá menos demanda e mais pontos de serviço.

Os serviços registrais e notariais têm investido, constantemente, em tecnologia para prestar um serviço cada vez mais rápido, preciso e integrado ao usuário. As centrais eletrônicas das diversas especialidades (Tabelionato de Notas, Tabelionato de Protesto, Registro Civil de Pessoas Naturais, Registro Civil de Pessoas Jurídicas e Títulos e Documentos, Registro de Imóveis) buscam integrar as informações em todo o país, conferindo ao usuário a possibilidade de solicitar serviços de um estado em outro, e inclusive realizar consulta de forma gratuita, como é o caso Central de Protesto - CENPROT, que permite a consulta sobre a existência de protesto em nível nacional. Isso possibilitou que os serviços notariais e de registro, considerados pelo $\mathrm{CNJ}$ como essenciais na pandemia da Covid-19 (Provimento $n^{\circ}$ 95/2020), continuem a atender, nesse período, os usuários de forma ininterrupta, mesmo que remotamente.

Ainda tendo em vista o período da pandemia, o CNJ publicou, conforme referido, a Recomendação n ${ }^{\circ} 46 / 2020$, que dispõe sobre medidas preventivas para que se evitem atos de violência patrimonial ou financeira contra pessoa idosa, especialmente vulnerável, no âmbito das serventias extrajudiciais e da execução dos serviços notariais. Entre as ações que serão fiscalizadas estão a antecipação de herança, movimentação indevida de contas bancárias e venda de imóveis. Havendo indício de qualquer tipo de violência patrimonial ou financeira, o fato deverá ser comunicado imediatamente ao Conselho Municipal do Idoso, Defensoria Pública, Polícia Civil ou Ministério Público. 
Ainda que os exemplos acima não sejam exaustivos, eles demonstram que é possível afirmar que os serviços notariais e de registro respondem, de forma notável, à nova ordem trazida pela $\mathrm{CF} / 88$, alargando as margens de sua atuação mediante a prestação de novos serviços e moderna roupagem, que contribuem, direta e indiretamente, para a melhoria social e econômica do país, configurando-se em importantes instrumentos para ao exercício da cidadania e a realização de direitos fundamentais.

\section{CONSIDERAÇÕES FINAIS}

A atividade notarial e de registro está presente na sociedade desde o surgimento da necessidade de segurança jurídica nas relações entre os indivíduos. A sua evolução deve acompanhar o desenvolvimento social. Dessa forma, o tratamento constitucional e legislativo outorgado à atividade deve ser consentâneo às necessidades sociais, permitindo a sua atuação para o cumprimento da função social que lhe é inerente.

O tabelião e o registrador são profissionais do direito dotados de fé pública, atributo este decorrente da função que exercem por delegação obtida mediante concurso público. No exercício de suas funções, respondem pessoalmente pelos seus atos, sendo plenamente responsáveis pela administração e condução dos serviços prestados à população. Com essa feição outorgada pela $\mathrm{CF} / 88$, a atividade notarial e de registro dinamizou-se, e passou a atuar em diversas frentes para cumprir a função social que lhe é inerente.

A configuração sui generis dos serviços notariais e de registro propicia uma atuação dinâmica voltada à ponderação entre os interesses particulares, sociais e econômicos, permitindo a sua ampliação como decorrência da estreita relação entre essa atividade extrajudicial e a segurança jurídica das relações sociais.

\section{REFERÊNCIAS}

AMADEI, Vicente de Abreu. A fé pública nas notas e nos registros. In: AMADEI, Vicente de Abreu; FIGUEIREDO, Marcelo; YOSHIDA, Consuelo Yatsuda Moromizato (Coord.). Direito notarial e registral avançado. São Paulo: Revista dos Tribunais, p. 35-53, 2014.

ASSOCIAÇÃO DOS NOTÁRIOS E REGISTRADORES DO BRASIL (ANOREG/BR). Cartório em números. 2020. Disponível em: https://www.anoreg.org.br/site/wpcontent/uploads/2020/11/Cart\%C3\%B3rios-em-N\%C3\%BAmeros-2-edi\%C3\%A7\%C3\%A3o2020.pdf. Acesso em: 11 dez. 2020. 
BORTZ, Marco Antonio Greco. A desjudicialização: um fenômeno histórico e global. Revista de Direito Notarial, v.1, n. 1, p. 76-110, jul-set. 2009.

BRASIL. Código Civil - Lei 10.406, de 10 de janeiro de 2002. Câmara Legislativa. Disponível em: http://www.planalto.gov.br/ccivil_03/leis/2002/110406compilada.htm. Acesso em: 04 mar. 2021.

BRASIL. Código de Processo Civil - Lei 13.105, de 16 de março de 2015. Câmara Legislativa. Disponível em: http://www.planalto.gov.br/ccivil_03/_ato20152018/2015/lei/113105.htm. Acesso em: 04 mar. 2021.

BRASIL. Supremo Tribunal Federal. ADI 3.089-2/DF. Rel. Min. Carlos Ayres Britto. Tribunal do Pleno. j. 13/02/2008. Diário da Justiça: Seção 1, Brasília, DF, 31 jul. 2008.

BRASIL. Supremo Tribunal Federal. Representantes dos três Poderes assinam pacto por Judiciário mais eficiente. 2004.

Disponível em: $<$ http://www.stf.jus.br/portal/cms/verNoticiaDetalhe.asp?idConteudo=63995\&caixaBusca=N>. Acesso em: 30 mai. 2018.

CARMO, Jairo Vasconcelos Rodrigues. Responsabilidade civil do delegatário. In: GONÇALVES, Vania Mara Nascimento. Direito notarial e registral, Rio de Janeiro: Forense, p. 73-99, 2008.

CARNELUTTI, Francesco. La figura giuridica del notaro. Rivista del notariato. Milano, anno 5, p. 1-14, 1951.

CENEVIVA, Walter. Lei dos notários e dos registradores comentada. São Paulo: Saraiva, 2002.

CONSELHO NACIONAL DE JUSTIÇA. Justiça em Números 2020: ano-base 2019/Conselho Nacional de Justiça - Brasília: CNJ, 2020. Disponível em: https://www.cnj.jus.br/wp-content/uploads/2020/08/WEB-V3-Justi\%C3\%A7a-emN\%C3\%BAmeros-2020-atualizado-em-25-08-2020.pdf. Acesso em: 04 mar 2021.

COTRIM NETO, Alberto Bittencourt. O aperfeiçoamento do notariado brasileiro: essencial para o aperfeiçoamento da justiça. Revista de Informação Legislativa, v. 11, n. 44, p. 143-152, out./dez. 1974

COUTURE, Eduardo J. El concepto de fe pública: Introducción al estudio del derecho notarial. Montevidéu: Ed. Univ. de Montevideo, 1954.

ERPEN, Décio Antônio. A atividade notarial e registral: uma organização social préjurídica. Revista Ajuris, Porto Alegre, V. 63, p. 269-280, 1995. 
FERREIRA, João Figueiredo. Para onde vão os cartórios? In: Evolução histórica. DIP, Ricardo; JACOMINO, Sérgio (Org.) Coleção doutrinas essenciais: direito registral, v. 7. São Paulo: Revista dos Tribunais, 2013.

FIGUEIREDO, Marcelo. Análise da importância da atividade notarial na prevenção de litígios e dos conflitos sociais. Revista de Direito Notarial, São Paulo, v. 2, n. 2, p. 11-124, 2010.

FISCHER, José Flávio Bueno; ROSA, Karin Regina Rick. Função Notarial Criadora do Direito. In: DIP, Ricardo; JACOMINO, Sérgio (Org.). Evolução histórica. Coleção doutrinas essenciais: direito registral, v. 7. São Paulo: Revista dos Tribunais, p. 511-573, 2013.

FORMICOLA, Tullio. O Notariado no Brasil e no Mundo. In: DIP, Ricardo; JACOMINO, Sérgio (Org.). Evolução histórica. Coleção doutrinas essenciais: direito registral, V. 08. São Paulo: Revista dos Tribunais, p. 1265-1274, 2013.

LIMA, Rui Cirne. Direito administrativo e direito privado. Rio de Janeiro: FGV, 1951.

MELLO, Celso Antônio Bandeira de. Curso de direito administrativo. São Paulo: Malheiros, 2005.

ORGANIZAÇÃO DAS NAÇÕES UNIDAS. Disponível em https://nacoesunidas.org/pos2015/agenda2030/. Acesso em 20 de agosto de 2019.

PEREIRA, M. Gonçalves. Notariado e burocracia. Coimbra: Coimbra Editora, 1994.

WAMBIER, Teresa Arruda Alvim et al. Breves comentários ao novo Código de Processo Civil. São Paulo: Revista dos Tribunais, 2015.

ZINNY, Mario Antonio. Fé pública notarial: El acto notarial (dación de fé). Tradução: Daisy Ehrhardt. Rio de Janeiro: Lumen Juris, 2018.

ZOCKUN, Maurício. Regime constitucional da atividade notarial e de registro. São Paulo: Malheiros, 2018. 